\title{
A PERMIAN MEGASECOPTERON FROM TEXAS ${ }^{1}$
}

\author{
By F. M. Carpenter \\ Harvard University
}

A collection of six Permian insects recently received from Dr. Sergius H. Mamay, of the U. S. Geological Survey, includes an unusually interesting species belonging to the extinct order Megasecoptera. The other specimens are fragments of cockroach wings, which, in the light of our present knowledge, cannot be satisfactorily placed in families and do not warrant description. The megasecopteron, however, is sufficiently well preserved to enable family and generic diagnoses. It clearly belongs to the family Bardohymenidae, of the suborder Eumegasecoptera.

\section{Family Bardohymenidae}

This family was based on Bardohymen magnipennifer Zal., from a Permian outcrop along the Barda River, near Perm, Russia (Zalessky, 1937). Two other genera, Sylvohymen Martynov (Permian of Oklahoma and of Chekarda, Russia) and Calohymen (Permian of Oklahoma) have also been placed here (Carpenter, 1947). The family includes species which are related to Protohymenidae but which differ in lacking the coalescences of Rs and $\mathrm{MA}$, and of MP and $\mathrm{CuA}$.

\section{Actinohymen, new genus}

Related to Bardohymen, but having the cross-vein between $\mathrm{R}_{\mathrm{I}}$ and $\mathrm{R}_{2}$ very strong, thickened at the costal end, and situated well basad of the apex of the wing. Pterostigmal area thickened; Rs with three main branches.

Type-species: Actinohymen russelli, n. sp.

\section{Actinohymen russelli, new species Text-figures $\mathrm{I}$ and 2 ; plate $\mathrm{I}$.}

Length of wing, as preserved, $28 \mathrm{~mm}$; width, $8.5 \mathrm{~mm}$; estimated complete wing length, $50 \mathrm{~mm}$. Wing markings: pterostigmal and

\footnotetext{
${ }^{1}$ This research has been aided by a grant from the National Science Foundation.

Manuscript received by the editor January 4, 1962.
} 
apical region margined with dark pigment; isolated triangular spots at end of $\mathrm{R}_{4}+5, \mathrm{MA}$, and $\mathrm{CuA}$. Eight outer cross-veins, forming a distinct row; $\mathrm{CuP}$ and $\mathrm{IA}$ forked distally. Other details of venation are shown in text-figure $\mathrm{I}$.

Holotype: No. I 40898, Paleozoic Catalogue \# 29, U. S. National Museum, Washington; collected by Dr. S. H. Mamay, in an outcrop on the Emily Irish land grant, about i 8 miles south-southeast of Seymour, Baylor County, Texas. The fossil is very clearly preserved and consists of about the distal half of a wing; the proximal half was apparently broken away in the counterpart, which is missing. Slight distortion of the anterior margin, just basal of the pterostigma, results from a pronounced depression in the rock. Although incomplete, this is the best-preserved specimen of a bardohymenid which has yet been found.

Geological age: Lower Permian; Belle Plains Formation (Wichita Group); this may be approximately correlated with the lower part of the Wellington Formation of Oklahoma and Kansas. (See Dunkle and Mamay, 1956; and Dunbar, et. al., 1960).

The species is named for Mr. Mart Russell, of Seymour, Texas, in recognition of the cooperation, hospitality and interest shown to Dr.

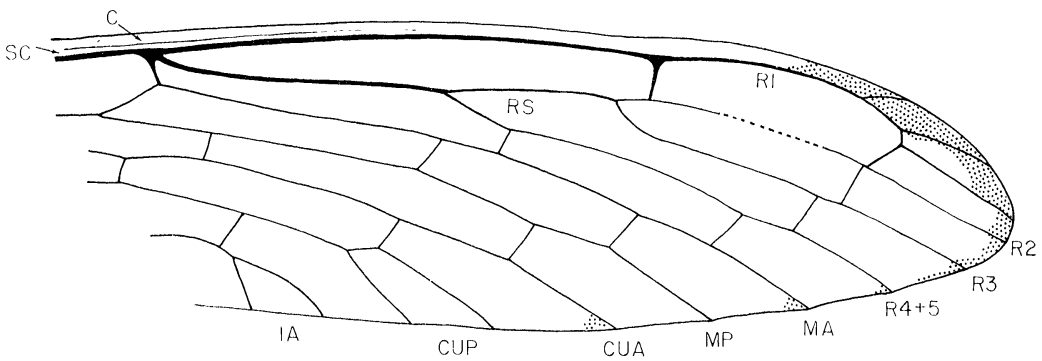

Text-figure 1. Drawing of Actinohymen russelli, n. sp., based on holotype. $\mathrm{C}$, costa (+) ; Sc, subcosta (-); R1, radius $(+)$; Rs, radial sector $(-)$; R2, R3, R4 +5, branches of radial sector (-); MA, anterior media $(+)$; $\mathrm{MP}$, posterior media (-); $\mathrm{CuA}$, anterior cubitus $(+)$; $\mathrm{CuP}$, posterior cubitus (-); $1 \mathrm{~A}$, first anal vein. The irregularities in the costal margin have been restored.

Mamay and his associates during their collecting trips at the Emily Irish deposit.

This remarkable fossil shows a number of interesting features, mostly specializations of the anterior marginal area of the wing. As in many Eumegasecoptera, such as Prothymenidae and Bardohy- 
menidae, the subcosta and radius ( $\left.\mathrm{R}_{\mathrm{I}}\right)$ are very close together and also to the anterior wing margin (text-figure 2). The costa is flattened and wide for its entire length. In the region of the pterostigma the costa widens even more and is somewhat thickened, but at the distal end of the pterostigma it disappears. The subcosta appears to be flattened and to be contiguous with the costa and is not readily distinguished from the latter. The radius $\left(R_{I}\right)$ is contiguous with the subcosta (in the preserved part of the fossil) or with the costa beyond the end of the subcosta, except in the very distal part of the wing. Beyond the short but distinct pterostigmal veinlet the radius seems to fork, the more distal branch leading to the very apex of the wing. The cross-vein at the basal part of the pterostigma forms a heavy bar, which is especially thick at its costal end.

The flattened costa, subcosta and even parts of $\mathrm{R}_{\mathrm{I}}$ bear several irregular rows of setal bases or sockets (text-figure 2), as in some

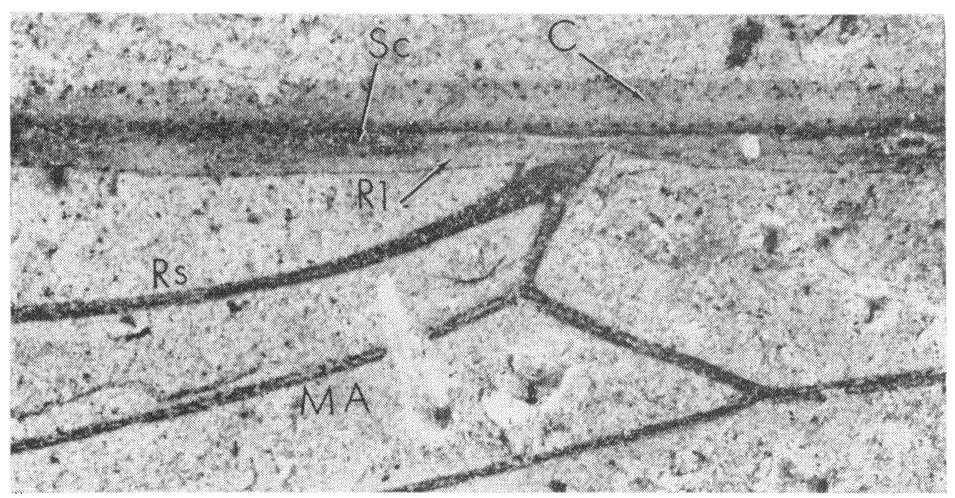

Text-figure 2. Photograph of part of wing of Actinohymen russelli, n. sp. (holotype), showing proximity of $\mathrm{C}$, Sc and R1, and the origins of Rs and MA. Setal bases can be seen along the costa.

Palaeodictyoptera, e. g. Dunbaria. It is curious that no setae are preserved, especially since they are often visible on the wings of Dunbaria.

The wing markings are not unlike those of other species of Megasecoptera, especially the Carboniferous Aspidothorax triangularis Brongn. (Commentry, France). Eumartynovia raaschi Carp. (Permian, Oklahoma), though not at all closely related (i. e., belonging to the Paramegasecoptera), has almost identical markings. 


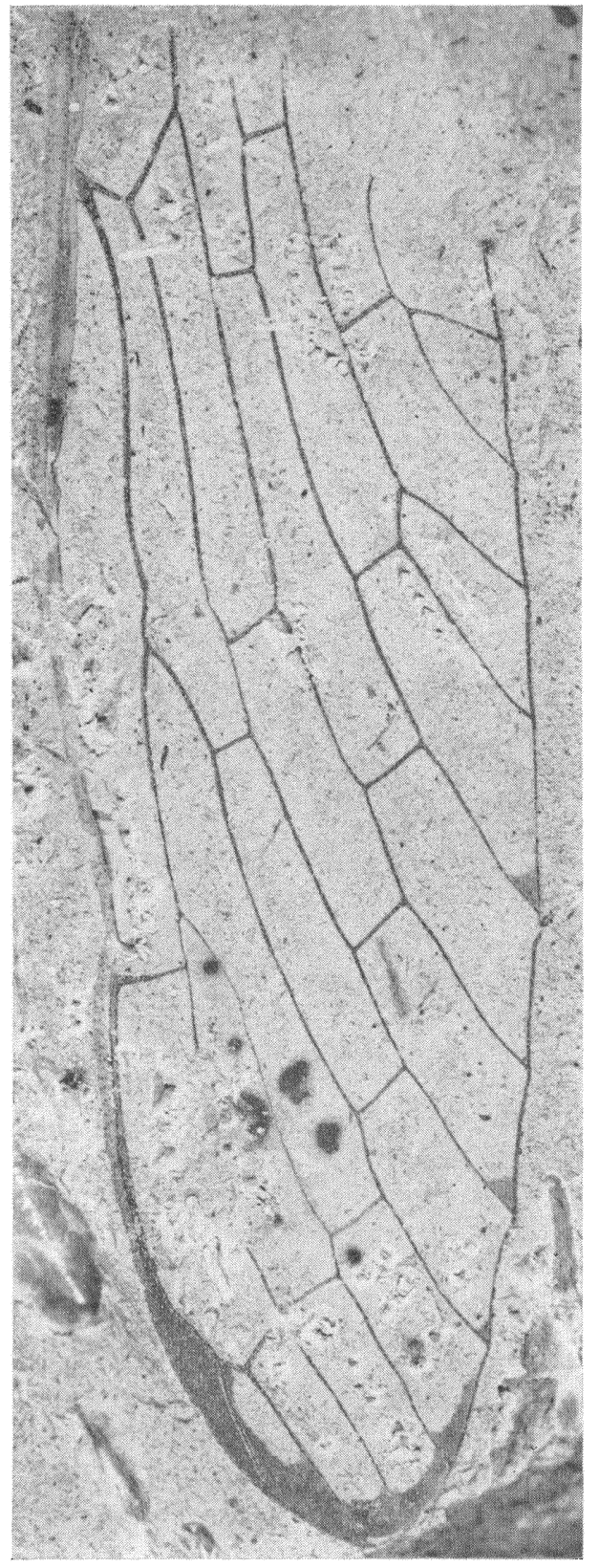




\section{References Cited}

Carpenter, F. M.

1947. Lower Permian insects from Oklahoma. Part I. Proc. Amer. Acad. Arts Sci. 76: 25.54.

DUnbar, C. O., et al.

1960. Correlation of the Permian formations of North America. Bull. Geol. Soc. Amer., 71:1763-1806.

Dunkle, D. H. and Sergius H. Mamay

1956. An acanthodian fish from the Lower Permian of Texas. Journ. Wash. Acad. Sciences, 46 (16) :308-310.

ZALESSKY, G.

1937. Etudes des insectes permiens du bassin de la Sylva et problèmes de l'evolution dans la classe des insectes. Prob. Paleont., 2-3; 601-607. 

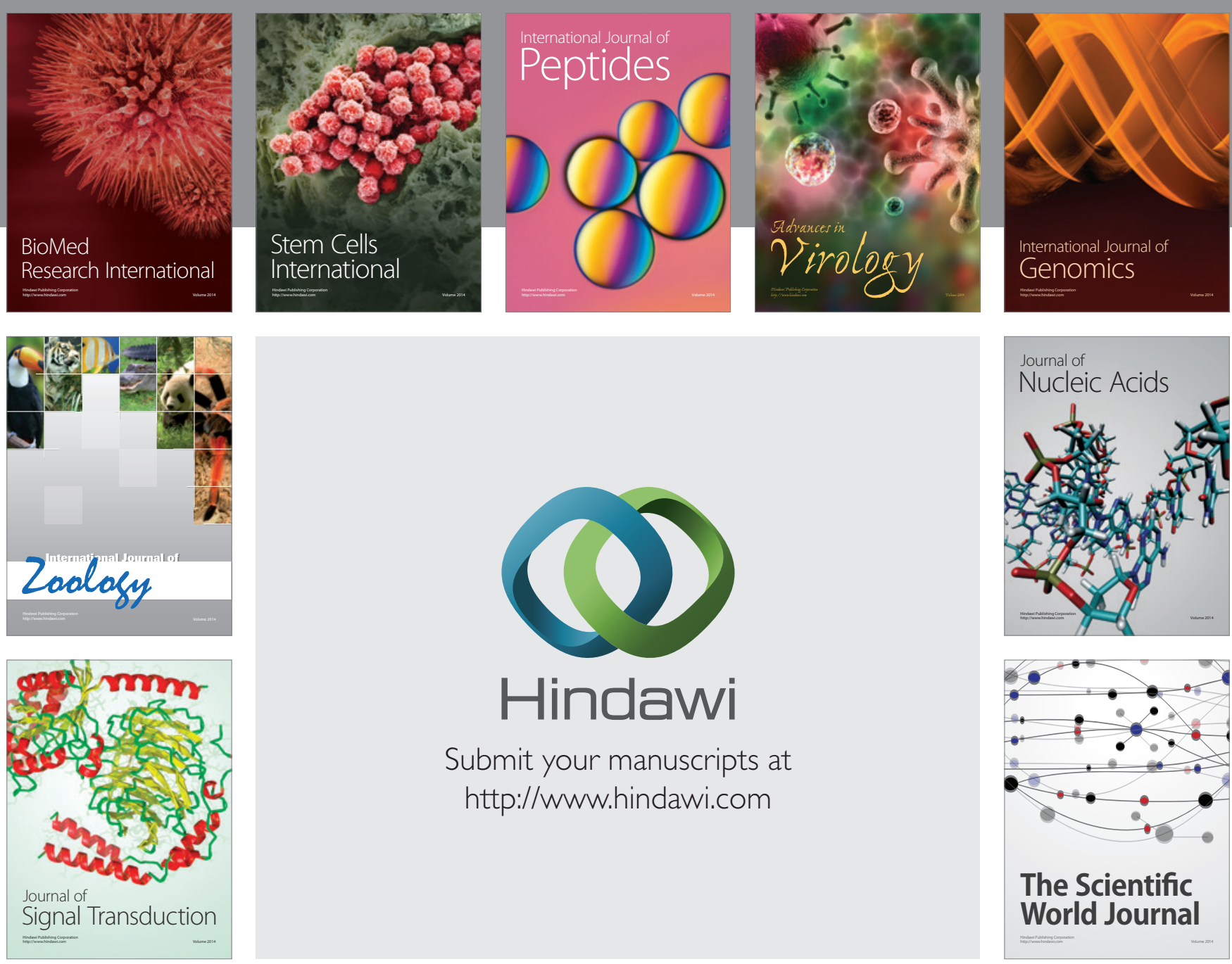

Submit your manuscripts at

http://www.hindawi.com
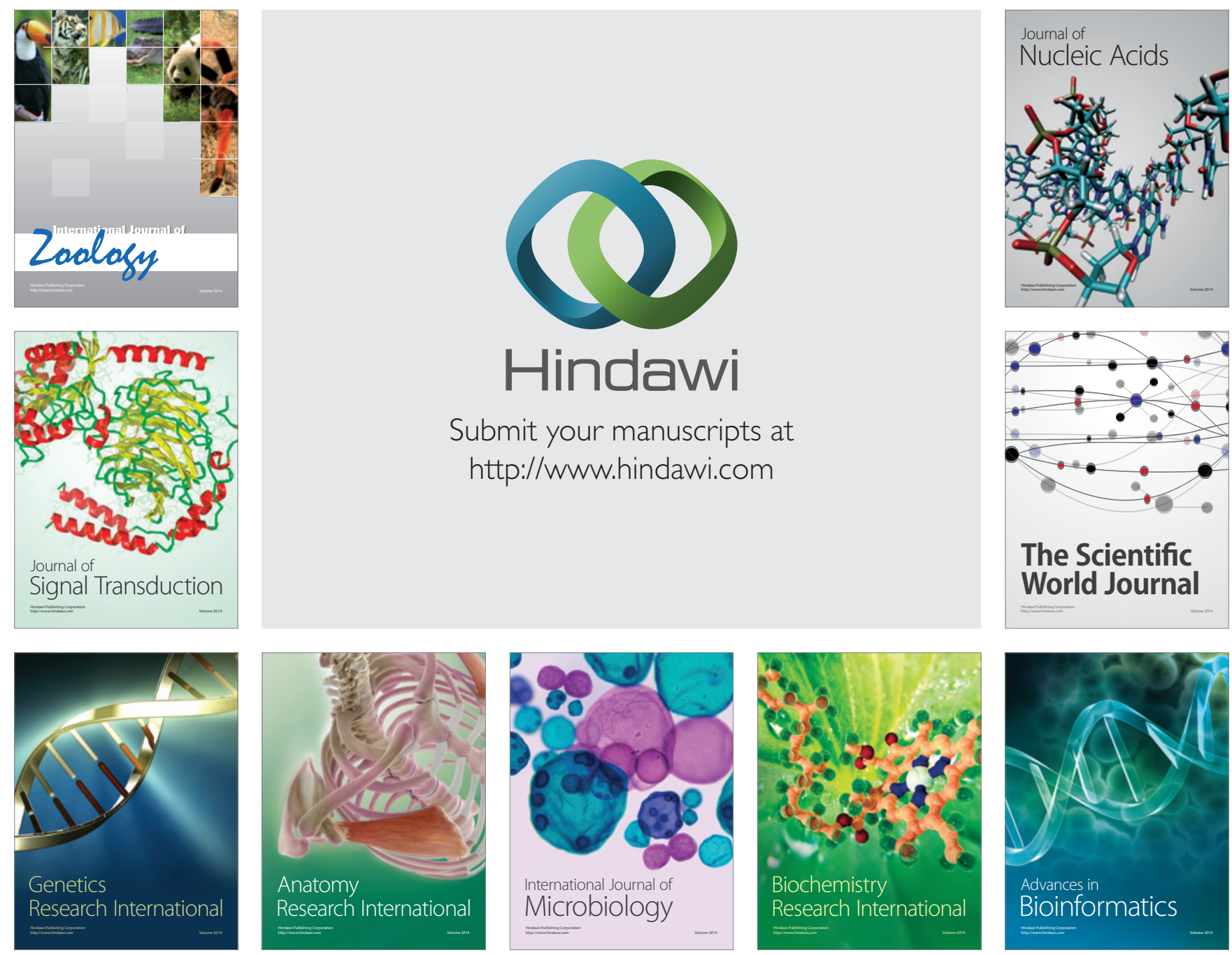

The Scientific World Journal
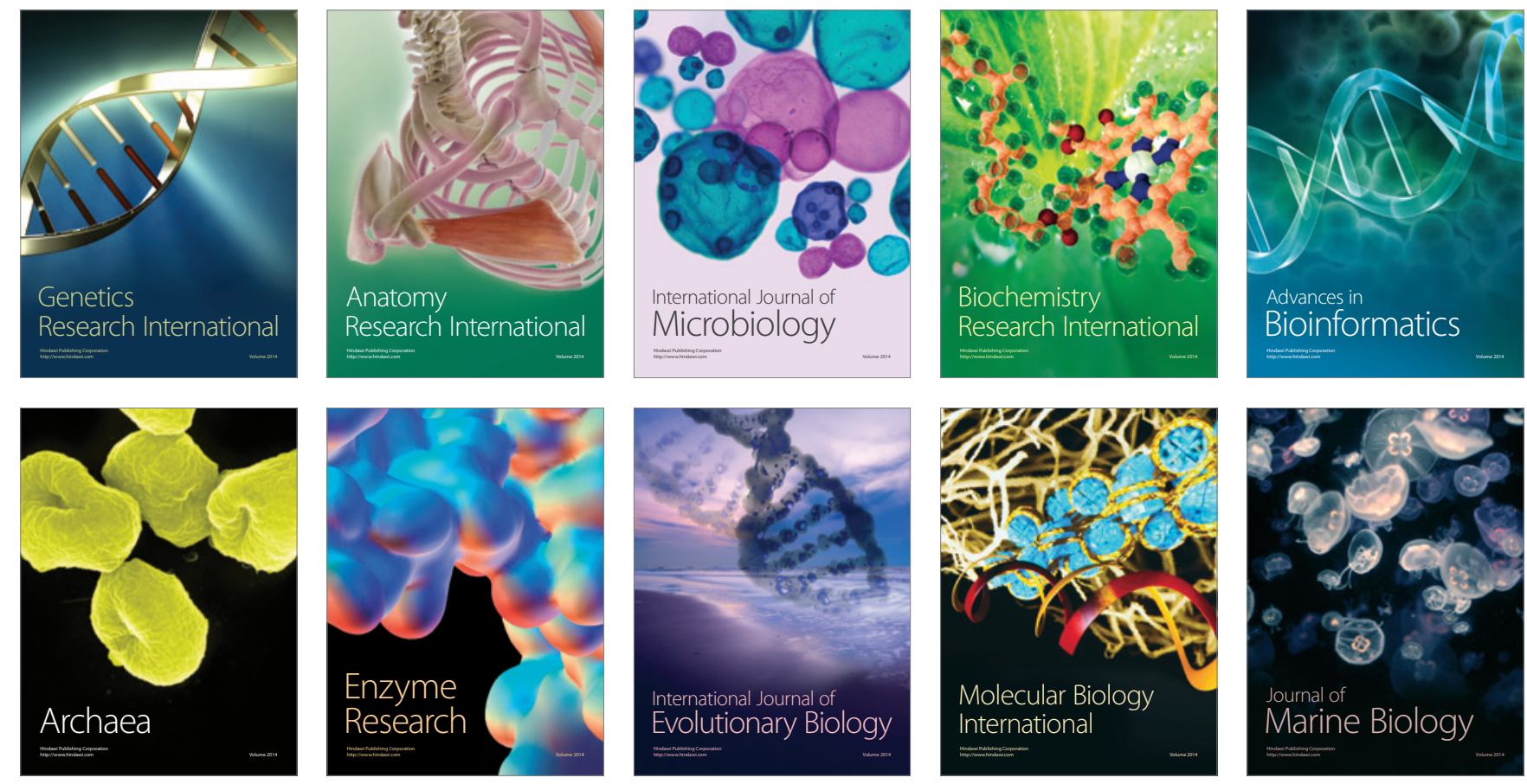